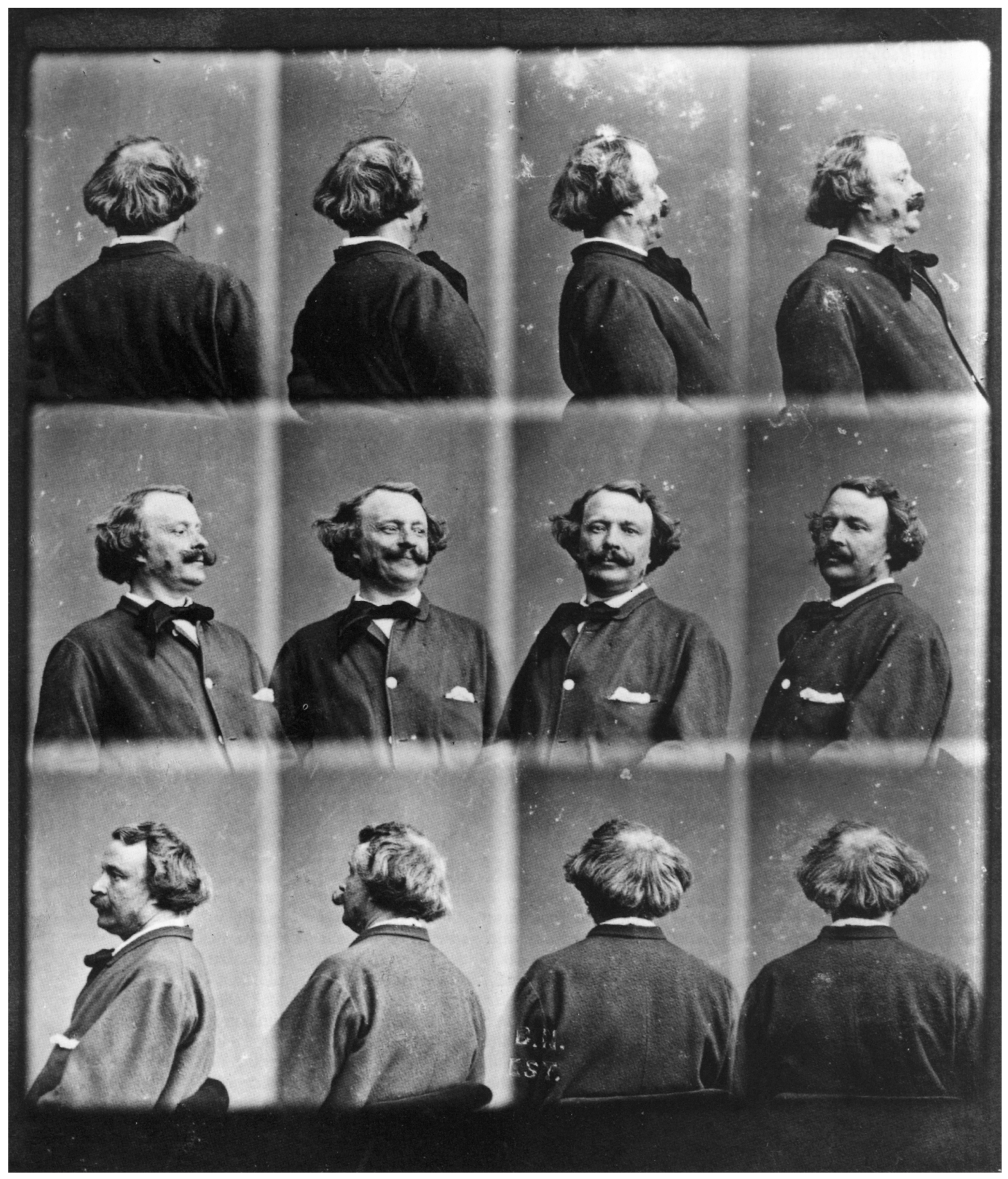




\section{Annateresa Fabris REIVINDICAÇÃO DE NADAR A SHERRIE LEVINE: AUTORIA E DIREITOS AUTORAIS NA FOTOGRAFIA}

Historiadora e professora titular (aposentada) da Escola de Comunicações e Artes da Universidade de São Paulo. e-mail: neapolis@bol.com.br

O conceito de direitos autorais, estabelecido logo após a Revolução Francesa, está indissoluvelmente ligado ao reconhecimento da figura do autor. Os fotógrafos oitocentistas são obrigados a travar uma longa batalha judicial para serem reconhecidos como autores, uma vez que a fotografia não era considerada arte, mas antes uma apropriação do real. Tendo como eixo a problemática da apropriação, este artigo indaga como tal conceito se transformou no século XX e como proporcionou uma redefinição não só da noção de autoria, mas da própria criação.

Em 1857, o fotógrafo Félix Tournachon move uma ação contra o irmão mais novo, Adrien, para evitar que este usasse o pseudônimo que o tornara famoso: Nadar. Na Reivindicação da propriedade exclusiva do pseudônimo Nadar, o fotógrafo estabelece uma clara distinção entre a fotografia como técnica, "cuja aplicação está ao alcance do último dos imbecis", e a fotografia como arte. Enquanto a primeira podia ser facilmente aprendida - a teoria fotográfica podia ser adquirida numa hora, as primeiras noções práticas num dia -, bem diferente era o estatuto da segunda, alicerçada no talento individual, numa visão particular e na capacidade de captar a fisionomia do modelo.

Não deixa de ser significativo que Nadar remeta a artisticidade da fotografia a dois atributos que podem ser considerados inatos. A seu ver, não era possível aprender nem o sentido da luz, nem a "inteligência moral" do sujeito. Na realidade, esses dois atributos acabavam confluindo numa dimensão única, pois cabia ao "artista" lançar mão de determinados efeitos luminosos, congeniais à fisionomia a ser retratada, para que esta revelasse a "semelhança íntima" do modelo'.

Ao usar esse tipo de argumentação, Nadar reclamava para si o status de artista e, logo, de autor, demonstrando que sua prática não se confundia com a função corriqueira atribuída à fotografia desde 1839. Se, em termos gerais, a fotografia era considerada uma reprodução do real, Nadar inscrevia sua prática no reino do espírito: suas imagens eram fruto de uma composição cuidadosa e tinham a capacidade de transmitir um sentimento, cuja raiz deveria ser procurada na transformação das aparências levada a cabo pelo fotógrafo.

Alguns anos mais tarde, a problemática da artisticidade da fotografia volta a ser discutida nos tribunais franceses graças ao processo Mayer-Pierson. Os dois fotógrafos, que podem ser inseridos na vertente industrial da fotografia, haviam realizado, em 1861, cartões de visita com as efígies de dois políticos estrangeiros, Palmerston e Cavour, reproduzidos abusivamente por outros profissionais (Betbeder e Schwabbe). Reclamando o próprio direito sobre as
1. FÉLIX NADAR.

"Revendication de la propriété exclusive di pseudonyme Nadar". In: MICHEL FRIZOT, FRANÇOISE DUCROS (org.). Du bon usage de la photographie. Paris, Centre National de la Photographie, 1987, p. 9. 
2. JOHN TAGG. The burden of representation: essays on photographies and histories. Amherst, The University of Massachusetts Press, 1988, p. 107-108.

3. Idem, p. 110.

4. Idem, ibidem. imagens realizadas, Mayer e Pierson solicitam a aplicação das leis sobre direitos autorais de 1793 e 1810 .

Tais leis haviam estabelecido uma clara equivalência entre o direito autoral e o direito de propriedade: nenhuma obra poderia ser publicada, traduzida, reproduzida, executada ou representada sem a autorização do autor. Embora as leis falassem em reprodução, sua aplicação à fotografia não é automática. Esta deveria ser considerada arte para poder contar com o amparo legal.

Caberia, pois, aos tribunais determinar se Mayer e Pierson eram artistas para que eles pudessem reclamar o direito à propriedade do próprio trabalho. A fotografia, no entanto, colocava um sério problema jurídico que Bernard Edelman denomina "sobreapropriação do real". Levando em conta a função realista atribuída à fotografia pela sociedade oitocentista, o autor pergunta: como a reprodução daquilo que era domínio comum poderia ser considerada propriedade de um fotógrafo? ${ }^{2}$.

A pergunta formulada por Edelman segue de perto o debate sobre a natureza da fotografia que toma conta do século XIX e que tem desdobramentos tanto estético-artísticos quanto jurídicos. Se no campo estético-artístico a fotografia é negada enquanto arte por ser um produto mecânico, o mesmo pode ser dito da visão dominante nos meios jurídicos. Em 1855, o Advogado Imperial Thomas estabelece a existência de duas temporalidades no trabalho fotográfico, quando afirma que os processos intelectuais e artísticos do fotógrafo são anteriores à execução material da imagem. O que significa que a fotografia é um produto mecânico, pois o espírito, a imaginação e a personalidade do sujeito não estão presentes ao longo de todo o processo ${ }^{3}$.

Idéias semelhantes são expressas em 1861 pelos Tribunais de Comércio de Turim e do Sena. Enquanto o primeiro sentencia que o fotógrafo realiza um trabalho puramente mecânico, sendo destituído dos atributos que caracterizam o artista (espírito, imaginação e, por vezes, gênio), o segundo reduz o ato fotográfico à feitura de estampas "que reproduzem a imagem dos objetos de maneira mecânica e de um jeito servil". O Tribunal de Turim dá um veredito que não oferece qualquer saída ao fotógrafo:

"o trabalho mecânico não pode, portanto, dar vida a produtos que possam ser legitimamente classificados entre as produções do espírito humano”.

É nesse clima cultural, que exclui a fotografia de qualquer atitude pessoal e interpretativa e, portanto, de qualquer direito de propriedade, que ocorre o processo Mayer-Pierson. Confirmando a visão negativa da fotografia dominante naquele momento, a primeira sentença, promulgada em janeiro de 1862, é desfavorável. O recurso, apresentado pelo advogado Marie em abril do mesmo ano, lança mão de uma argumentação retórica que derruba as teses contrárias à fotografia graças à equação arte=beleza=verdade em sua realidade material. 
A partir dela, afirma Marie:

"Se nós vemos a verdade na fotografia, e se a verdade em sua forma exterior fascina o olho, como pode, então, deixar de ser beleza? E se aqui se encontram todas as características da arte, como pode não ser arte? Pois bem! Protesto em nome da filosofia"

Além de reclamar artisticidade para a fotografia, Marie lembra aos juízes que a atitude mimética não é exclusiva da nova imagem, devendo ser estendida à pintura. Verdade e beleza, na realidade, são atributos tanto da fotografia quanto das artes plásticas. O processo criador é semelhante em todos os casos: o fotógrafo, num primeiro momento, compõe uma imagem com sua fantasia; num segundo momento, capta com a câmara o que sua inteligência concebeu e o transmite à obra ${ }^{6}$.

Os argumentos de Marie, que solicita a aplicação da lei emanada pela Convenção Nacional em 1793, convencem o tribunal que, em julho de 1862, dá ganho de causa a Mayer e Pierson, declarando que a fotografia era uma arte passível de proteção em termos de propriedade intelectual.

A vitória de Mayer e Pierson não implica automaticamente o reconhecimento legal da fotografia como arte. E tal reconhecimento é fundamental, pois, como lembra John Tagg, são os tribunais que executam "o difícil trabalho ideológico de separar o uso instrumental da fotografia de sua função como arte, que estava ligada a seu valor de uso". De acordo com o autor, o reconhecimento do caráter criativo da fotografia processa-se em duas etapas. Na primeira, os legisladores são surpreendidos pela irrupção de novas técnicas mecânicas de reprodução do real, que se confrontam com dois tipos de arte: "manuais" e "intelectuais". Vista como um "trabalho destituído de espírito", a fotografia não é considerada digna de figurar no âmbito da criação por uma sociedade que havia estabelecido um elo inextricável entre individualidade, criatividade e propriedade. Quando a fotografia, entre a década de 80 e os primeiros anos do século XX, adquire uma dimensão industrial, acaba por ter reconhecida a própria criatividade. Estabelece-se, nesse momento, uma mediação entre imagem técnica e realidade graças a um conceito como "marca de personalidade". O aparato, desse modo, torna-se um simples mediador, dominado por um sujeito ativo; torna-se veículo da "alma do Homem", "cuja essência é a propriedade privada”, como sublinha Tagg ${ }^{7}$.

Não há contradição ou paradoxo na condição artística finalmente alcançada pela fotografia num momento em que sua transformação em indústria não poderia prescindir do amparo da lei para proteger os profissionais contra o perigo de uma concorrência desleal. Em termos legislativos aplicam-se à fotografia as categorias da propriedade literária e as características fundamentais da personalidade, o que deixa claro que, para a lei, "cada processo é fundamentalmente o processo de um sujeito"s.
5. AARON SCHARF. Art and photography. Harmondsworth, Penguin Books, 1974 p. 151 .

6. Idem, ibidem

7. JOHN TAGG,

Op. cit., p. 104, 108-109, 112-113.

8. Idem, p. 115. 
9. PHILIPPE DUBOIS. $\mathrm{O}$ ato fotográfico e outros ensaios. Campinas, Papirus, 1998, p. 167 .

10. EDMOND COUCHOT. La technologie dans l'art: de la photographie à la réalité virtuelle. Nîmes, Éditions Jacqueline Chambon, 1998, p. 21.

11. JOHN TAGG. Op. cit., p. 106.
Se não existe um paradoxo social no reconhecimento da fotografia como arte, não se pode deixar de assinalar que o debate sobre as possibilidades criativas da imagem técnica faz passar para o segundo plano as efetivas inovações de que ela era portadora, inovações que investem justamente a esfera do sujeito. Não se pode esquecer que, num primeiro momento, a gênese automática da imagem, longe de constituir um obstáculo, é a prova inequívoca da superioridade do daguerreótipo e da fotografia em relação às técnicas convencionais. Liberta da mão do artista e, portanto, de interpretações e imperfeições, a imagem técnica garante uma exatidão e uma precisão que a colocavam a salvo da subjetividade do operador tradicional.

A contestação do sujeito criador, proposta pela fotografia em pleno regime romântico, volta-se contra ela quando a nova imagem tenta ser aceita como arte e busca determinar legalmente o direito à propriedade intelectual. Os argumentos usados por seus detratores e seus defensores são hoje passíveis de muitas críticas, pois vêm carregados de inúmeros equívocos. É o que se verifica sobretudo na análise do processo criador, para o qual se tenta estabelecer uma equivalência perfeita entre imagem técnica e imagem manual, sem levar em conta o fato de que existem diferenças substanciais entre o corte fotográfico, que ocorre de uma só vez e de maneira global, e a composição pictórica, que se estrutura progressivamente ${ }^{9}$.

Esse aspecto diferencial da fotografia em relação à pintura é também enfatizado por Edmond Couchot. Para ele, a fotografia oferece ao espectador "aquele instante originário em que se encontram reunidos, co-presentes num mesmo lugar o sujeito, o objeto e a imagem (latente), de uma maneira quase totalmente automática”. Se o início do processo de automatização da imagem pode ser reportado ao século XV - quando começam a ser usados instrumentos automáticos na composição pictórica, levando Couchot a falar num "sujeito aparelhado" -, não se pode esquecer que o artista continua a ser considerado fundamentalmente um "sujeito singular". Esse quadro de referências será modificado pela fotografia, que automatiza o antigo trabalho manual e reduz drasticamente o tempo da composição da imagem, levando os artistas a enfatizarem as qualidades intrínsecas da arte, ausentes na nova imagem: singularidade e individualidade ${ }^{10}$.

Os vários momentos em que a fotografia luta para ser reconhecida como arte - exemplificados aqui com a petição de Nadar e com o processo Mayer-Pierson - caracterizam-se pelo uso de categorias artísticas tradicionais e, sobretudo, pela convergência entre pessoa e sujeito em termos legais. No Código Civil francês a doutrina da propriedade deriva da propriedade do sujeito como dono de si mesmo, do próprio trabalho e dos próprios produtos ${ }^{11}$, e isso deve explicar o caminho legal escolhido por Nadar e por Mayer e Pierson, que se vêem como indivíduos criadores. 
O que está em jogo nessa disputa é o conceito de realidade e é em seu nome que a fotografia verá negado, num primeiro momento, seu acesso à propriedade intelectual. As implicações ideológicas do conceito de realidade e a homologia que se estabelece entre a objetividade fotográfica e a visão de mundo burguesa estão na base da distinção jurídica entre criação e reprodução. Considerada um "produto natural"- como os próprios pioneiros da fotografia não se cansavam de sublinhar -, a nova imagem não era passível de proteção legal por não ser um produto do espírito.

Na tentativa de ver a imagem técnica reconhecida como arte e de ter acesso à proteção legal, os fotógrafos do século XIX procuram negar não só a mediação do aparato, mas também uma das características principais da fotografia: a apropriação do real de maneira não estilizada. Se isso era um óbice para os defensores dos princípios artísticos tradicionais - pois a fotografia não seria investida pela personalidade criadora $^{12}$-, não se pode esquecer que a apropriação será uma das estratégias fundamentais da arte do século XX.

Se lembrarmos que, com o ready-made, Duchamp põe fim ao predomínio da arte em prol da esfera estética - denunciando o caráter (ainda) romântico da figura do artista -, e se lembrarmos que o objeto é substituído pelo signo, não será abusado ver nessa atitude radical uma proximidade com o princípio fotográfico, que desconhece as antigas hierarquias e se apropria indistintamente de todos os aspectos da realidade.

Embora Anne Cauquelin não estabeleça qualquer vínculo entre Duchamp e a fotografia, algumas considerações presentes em $A$ arte contemporânea podem ser extrapoladas e aplicadas à nossa análise: a idéia de que o autor desaparece enquanto fazedor para tornar-se aquele que mostra; o lembrete de que o ready-made não pode ser dissociado do "continente temporal", pois a escolha do objeto pertence ao acaso, ao encontro, à ocasião; a concepção do artista como produtor, ou seja, como alguém que abdica da criação a favor da utilização do material e do deslocamento do objeto em termos de lugar e de temporalidade ${ }^{13}$.

A fotografia, pois, é um elemento que não pode ser esquecido no momento em que se discute um novo papel para o artista e em que a habilidade técnica deixa de ser um requisito fundamental na produção de um objeto artístico. Apesar de todas as tentativas de aproximação entre fotografia e artes plásticas, é impossível deixar de lembrar a relação entre o fotógrafo e a câmara, entre o fotógrafo e o dispositivo tecnológico pontualmente utilizado.

Não por acaso, Edmond Couchot faz referência ao confronto entre dois tipos de subjetividade que, surgido no Renascimento, ganha uma nova dimensão com a fotografia e com a autonomia cada vez maior dos processos automáticos de configuração da imagem. Haveria uma negociação constante entre um sujeito pessoal, portador de uma subjetividade "irredutível a todo
12. Idem, p. 108.

13. ANNE CAUQUELIN.

A arte contemporânea.

Porto,

Rés-Editora, s. d., p. $83-85$ 
14. COUCHOT, Op. cit., p. 10-11.

15. ROSALIND KRAUSS Bachelors. CambridgeLondon, The MIT Press, 2000, p. 180

16. "Five comments by Sherrie Levine". In, V. A. Special affects: the photographic experience in contemporary art. Milano, Politi, 1989, p. 177.

17. DOMINIQUE BAQUÉ. La photographie plasticienne: un art paradoxal. Paris, Éditions du Regard, 1998, p. 180-181; DANIELA SALVIONI

"Conjunction and disjunction". In: V. A. Special affects: the photographic experience in contemporary art.

Op. cit., p. 15.

18. KRAUSS, Op. cit., p. 190.

19. SALVIONI, Op. cit., p. 15. mecanismo técnico e a todo hábito perceptivo", e um sujeito impessoal, modelado pela experiência tecno-estética. Do confronto entre esses dois sujeitos e, sobretudo, da resistência do sujeito pessoal ao predomínio tecnológico e à redefinição da própria identidade, se originaram crises sucessivas "que afetam violentamente o mundo da arte" ${ }^{14}$.

Uma das encarnações mais radicais do sujeito impessoal é Sherrie Levine, para cujos trabalhos Rosalind Krauss não hesita em utilizar - positivamente - o termo "pirataria" ${ }^{15}$. Em quê consiste a atitude da artista americana? Em refotografar imagens de autoria de fotógrafos famosos, encontradas em livros e revistas, radicalizando ainda mais o gesto de apropriação duchampiano. A mola-mestra da atitude de Sherrie Levine deve ser buscada na idéia de que toda obra é um tecido de citações e de que os artistas contemporâneos só podem "imitar um gesto que é sempre anterior, nunca original" ${ }^{16}$. Fiel a tais pressupostos, que a levam a proclamar a própria afinidade com o Borges de Pierre Menard, a artista não só coloca em xeque as noções de autoria, obra e originalidade, como traz para o primeiro plano a problemática da mediação tecnológica e, logo, de um universo cultural no qual a mitologia do gênio está sendo erodida junto com as idéias de raridade e valor ${ }^{17}$.

Se o "efeito Levine" consiste em afirmar a existência de um mundo no qual os nomes próprios formam uma série entre si, no qual o nome não significa mais nada, embora continue sendo produtivo ${ }^{18}$, é evidente que não se pode mais pensar a problemática da autoria nos termos propostos pela crítica moderna. Nos antípodas da legislação oitocentista, a atitude desconstrucionista da artista americana acaba por conferir plena legitimidade ao ato fotográfico, uma vez que a mediação tecnológica é assumida como sujeito e objeto da obra de $\operatorname{arte}^{19}$. E o fato de que suas imagens gozem de proteção legal não é um paradoxo. Trata-se do reconhecimento de uma nova concepção de autoria para a qual a fotografia deu uma contribuição decisiva, ao obliterar o primado da mão e ao chamar a atenção para o papel fundamental da técnica como conformadora da imagem. 